\title{
Canine agents in two South African short stories
}

\author{
Mathilda Slabbert \\ Mathilda Slabbert is a Senior Lecturer in the Department of English Studies at the \\ University of Stellenbosch, South Africa. \\ Email: mslabbert@sun.ac.za
}

\section{Canine agents in two South African short stories}

This article explores the role of the figure of the dog in two contemporary South African short stories. It considers the metaphorical-cum-allegorical significance of the textual animal in these texts, asking how the writers use dogs as imaginative devices to draw attention to issues of gender, human emotions or psychoses, and the avowal or disavowal of (human and animal) agency. The aim is to engage with the writers' evident wish both to comment on human-animal relationships and encounters in contemporary South African society, and to emphasise how these become effective, affective means of commenting on the continued inequities of post-apartheid society. Keywords: dogs; gender; short fiction; textual dogs.

\section{Introduction}

Dogs have long been a heated topic in contemporary South African news media and in political discourse, ranging from discussion about dogfights to President Jacob Zuma's comment during a speech in 2012 that keeping pet dogs is not African (News24). The 'dog' has also been a much debated, often controversial, figure in South African literary and cultural studies, as evidenced in scholarship on Marlene van Niekerk's Triomf (1994), J. M. Coetzee’s Disgrace (2000), and Daniel Naudés photographs of Africanis dogs (see Libin; Attridge; Baderoon).

In this paper, using two stories, I offer a literary analysis of the representation of the figure of the dog, hoping to understand the work done by the dog as textual figure in these narratives. I focus on two South African short stories, published in the last decade, namely "The Life of Worm" by Ken Barris (2017), and "How to Carry On” by Sally-Ann Murray (2015). ${ }^{1}$

My discussion considers the metaphorical or allegorical significance of the dog in these texts, asking how the writers use dogs as imaginative devices to draw attention to issues of gender, human emotions or psychoses, and the avowal or 
disavowal of (human and nonhuman) agency. ${ }^{2}$ My interpretation seeks to show how the authors strategically accentuate their human self-reflexivity via the figure of the dog, such that 'the dog' becomes a powerful trope in the narrative patterning, a telling motif that enables an author to limn complex human-animal relations in the resonant, compressed space of short fiction. In turn, by unpacking the trope of the dog in these stories, I aim to initiate a further, multifaceted imaginative conversation between the texts, and between mediated animal-human life worlds. I engage with the writers' evident wish both to comment on human-animal relationships and encounters in contemporary South African society, and to emphasise how such relationships and encounters become an effective affective means of commenting on the continued inequities of post-apartheid society.

In "Literary Animal Agents" (2009), Susan McHugh, akin to other animal studies scholars, calls for a "complex dynamics of reading literary animal" signification (488). She advocates methods that interpret the "textual animal" not as analogy or "substitute for human subjects in the making" only (488), but also as an agent that evokes questions about histories, current conditions, and agency of species. This line of inquiry aligns with Wendy Woodward's approach in her study on dogs in South African fiction. She "consider[s] whether the writers conceptualise dogs as capable of selfhood which can be exemplified in intentionality, agency, cognition and emotions and/or whether dogs function metonymically" (237). I concur with McHugh's emphasis on the highly mediated correlation between empirical being and textual referent. My interpretation develops the element of the textual nature of the animals we find in fiction, also advocated by critics such as Mario Ortiz Robles, who studies represented animals as "literary inventions", not 'real' animals. These freighted creative creatures are constructed through the "verbal [written] inventions of humans" (Robles 2), and thus necessarily share oblique kinship with the living and breathing dogs (for example) who share our lives and living spaces. In short, my exploration proceeds from my attention to "the doglike $\operatorname{dog}[\mathrm{s}]$ " (Robles 57) represented in the chosen stories.

Both writers use dogs as imaginative devices to comment on issues of gender. Drawing on Jacklyn Cock's ideas about the histories and consequences of "the ideology of militarism", warfare and militarisation in South Africa, on masculine behaviour, as well as scholarship on "violent masculinity" (Gqola 118), I focus in the analysis of Barris' story on the representation of 'militant masculinity'. Cock and Pumla Dineo Gqola, amongst others, discuss how the ideology of militarism continues to manifest in abusive acts (explicit or disguised; physical or discursive) against those who are deemed vulnerable, among them women, children, and non-heteronormative individuals (a person who does not align with views that heterosexual orientation is the only norm, i.e. members of Lesbian, Gay, Bisexual, Transgender, Queer, Intersex communities). My analysis of Murray's story focuses on how her use of the dog serves to address the vulnerability of "non-binary gen- 
Canine agents in two South African short stories

ders" (Richards et al 95), particularly transgender, characters and amplifies the shortcomings of linguistic gender distinctions, and the impact on gender performativity. ${ }^{3}$ I use transgender with an understanding that "recognise[s] the diversity of transgender subjectivities" (Hines 49), and that the term 'trans' designates, according to queer theorist Jack/Judith Halberstam, "an unknowability about what the meaning of trans activity might be in relationship to any gender variant body" (n. p.). Pivotal to both gender politics readings is the vulnerable animal/ dog, and how this fragility is entangled, in the stories, with various (marginalised) identities.

Before proceeding, the crucial questions: Why short stories, and why these particular stories? Craig MacKenzie states that South African literature "is particularly rich in the genre" (v) of the short story; whereas, as Michael Chapman notes, the long-form prose of the novel brings South African authors "the largest reputation" (285). Being a successful novelist not only affords an author more status (and perhaps eligibility for awards); novels receive more scholarly attention. On an academic scale, then, the short story could be said to occupy the proverbial position of 'underdog', and this paper wishes to reclaim this abjected form, figuratively 'giving voice' to the more marginal literary animal that is 'the short story'. Furthermore, it is evident that contemporary South African fiction writers (whether in long or short form prose), "appear to be enjoying greater thematic freedoms" than in the past, along with the desire to "tak[e] greater aesthetic risks" (Kostelac 54-5). Thematic freedoms include unusual combinations of attention to issues of gender and sexuality, class, crime, disease, and ecology, topics often neglected in apartheid and transition period narratives, which inclined very overtly to address the demands of an expressly politicised, racialised discourse. In terms of aesthetic risks, we see local fiction writers experimenting with, amongst others, discourses of self-reflexivity, such as metafictional techniques, rupturing the surface of the assumed 'real' in order deliberately, even doggedly, to "comment $[\ldots]$ on the fictionality and/or constructedness of the narrative" (Neumann and Nünning n. p.), breaking the conventionally established assumptions of creative mimesis in favour of uneasy fictional worlding that might discomfort the reader. This clearly connects with my interest in the 'dog' in fiction functioning not as unmediated material being but as purposive textual device. The selected stories are interesting examples of these developments in creative writings, in which the authors' use of the figure of the dog is particularly arresting. The two stories are by no means the only examples from the demarcated period in which dogs (or other animals) feature either as primary characters or as referents. However, the Barris and Murray stories can be regarded as explicitly "canid texts" (Robles 57), since the dogs are central to narrative conflict.

The narratives share a number of similarities. Both, for example, work beyond naturalised assumptions of the dog as domestic pet, and feature the trope of the

Tydskrif vir Letterkunde 55.3 (2018) 
companion dog, or longed-for companion dog. This recalls Donna J. Haraway's phrase "companion species", and reminds us that the human and dog species in the stories "share their otherness in a [...] space" along with "other affects that transit between species" (Robles 70). The represented dogs are not domesticated pets that co-inhabit a space where they "flourish alongside humans" (McHugh 490) in a conducive, mutually caring relationship (Armbruster "Good Dog': The Stories We Tell about Our Canine Companions and What They Mean for Humans and Other Animals" 371). Instead, the dogs disrupt comfortably established norms of human and humane sociality by highlighting the vulnerability of human and animal subjects. Additionally, both the stories feature unnamed first-person narrators, human or dog characters; the dog walk as a purposive local conceptual configuration of the more habituated abstract narrative motif of the 'journey'; and the mapping of public and/or domestic spaces in and near an urban context (in the Western Cape). These connections, guided by the trope of the dog, allow me to consider a "possible distillation" (Heyns 168) between the narratives, in that they comment on issues in contemporary South African society, while they implicitly or explicitly align these with socio-political concerns from the past.

So as not to get embroiled in spurious debates about the relationship of metaphor and allegory, I frame my exploration of the dog as figurative device within the refreshingly clear ambit of Arran Stibbe's definition: metaphor is "a story that describes something as if it were something else" (63), which aligns with George Lakoff and Mark Johnson's idea that "metaphor is understanding and experiencing one kind of thing in terms of another" (5). Allegory relates to metaphor in that an "allegorical image" can be "metaphorical in character" to "create a sense of a resemblance which is not consciously remarked on" (Tambling 4). Useful criticisms discussed by Jeremy Tambling argue: different tropes in a text "say something 'other' from each other" and "form allegory [...] in the ways they are laid alongside each other": when similar tropes, allegorical writing in different texts are compared, they can speak to each other "through the power of allegory" (144).

\section{Worming masculinity}

In "The Life of Worm" Barris takes as his key themes the issues of crime, fear, territorialisation and (male) paranoia. I focus on the metaphorical, allegorical significance of the dog figure to consider what the depiction suggests about the national fixation with crime, militant masculinity, and how the psychoses and violent desires of the human character are transferred to the dog through acts of oppression and domination to be embodied by the dog.

Narrated from a first-person perspective, Barris' story is the account of a troubled, unnamed man who lives alone, but with his dog, Worm. The story is set in or near the suburbs of Bel Ombre or Constantia Heights in Cape Town, inferred

Tydskrif vir Letterkunde 55.3 (20I8) 
Canine agents in two South African short stories

from the routes described: the narrator walks Worm down "Avenue Picardie", "Avenue Provence", and "Avenue Le Sueur" to the nearby "green belt" $(23,33,34){ }^{4}$ These, along with other signifiers, are highly localised, specific identifiers, yet in not naming the human protagonist, Barris seems to imply that narrative events could happen in any urban context in South Africa, and therefore the story seems implicitly allegorical.

Structurally, the story develops in the frame between two dog walks. It begins with the narrator telling the reader about his dangerous dog, and the precautions he has to take to walk Worm. His emphasis on the dog's "muscularity" that "bristles at the thought of violence" (22) creates a sense of foreboding. On the first walk, they happen on an elderly woman with a small dog, and while the narrator tries to avoid her, to his great "consternation" (25) she walks up to Worm, "takes both his cheeks in her hands", and promptly declares him "a love" (25). Worm, who ignores the woman's dog, is enthralled by her attention, wags his tail and "makes excited guttural noises" (25). Thus we learn (something which the abject name has already hinted) that Worm is not the dog he is proposed (indeed, supposed) to be, and with this discrepant narrative opening, Barris points to the warm spontaneity, friendly and caring potential of a dog which the narrator has pronounced to be "potentially psychotic" (22), a canine warning. By the end of the story, on the second walk, the narrator and Worm encounter "a cocker spaniel", and on this occasion, Worm "proceeds to attack the animal", strangles it, and refuses to "release" (34-5). The act is interpreted by the narrator as "the completion of his [Worm's] nature" (35). However, in the space of the story, what transpires between these two walks allows us to track, so to speak, the circumstances and conditions that produce the behavioural change in Worm. Barris makes it clear that the narrator's violent, militant masculinity is a key agent in enacting the relationship between man and animal, these characteristics being transferred to the dog.

The narrator's distress stems from his obsession with crime and other "threat[s] to his security" (26). That such threats include his neighbour's oak tree growing "next to [their] shared boundary wall" (26) is telling in respect of his delineation of both spatial and discursive boundaries. Ownership is amplified in the repetition of the personal possessive: "my garage", "my car", "my house", "my lounge", "my only heritage" (27-8), and "my dog" (25). The narrator has taken excessive precautions against crime in a manner typical of middle-class and more affluent South Africans. The property is cordoned off with high walls, electric gates, and fencing. He has installed burglar alarms, external beams, and infra-red motion sensors, while a steel gate inside blocks off the three bedrooms (one completely empty) from the rest of the house. LEDs monitor electricity "charge" (28); emergency batteries are on standby in case of power cuts, and he frets about not yet having purchased a generator. To ensure defences function at full capacity, the narrator "follow[s] a certain protocol at night" (28), performed (and narrated)

Tydskrif vir Letterkunde 55.3 (2018) 
with military precision, finally leaving him [and Worm] safely barricaded inside the bedroom section. Ideally, he would like Worm to stay outside, but the neighbours have complained about the incessant barking, and the dog-clearly lonely, bored and anxious-has to be tolerated indoors with his "flabby lips" (32). Security check completed, the narrator is free "to read, watch television", "listen to music", or to "prowl the internet" (30). Prowling, in a very voyeuristic fashion (suggestive of his own preying nature), includes "keep[ing] track of incidents in [the] area through the local Neighbourhood Watch website", "suspicious vehicles" and images of people "who are suspected of being a danger to the area" (30-1), and conducting layman's research about criminal behaviour (about which he seems knowledgeable). Ironically, his thoughts about 'dangerous' people, "criminals [who] are just as sensitive as we are" (28; my emphasis), later prove him complicit in this grouping because he and Worm are involved in a crime that makes them dangerous to animals and humans alike. The ambiguous use of 'we' gestures at once to the narrator and Worm, as well as to an implied audience of likeminded locals who might share the narrator's views (and neurosis) and homogenise all crimes and criminals as 'other', while ignoring their own levels of complicity. The mode and tone of the narration accentuate Barris' satirical commentary on the social pathology and realities of contemporary South Africa: the precarity of a democratic civic, evident in the preoccupation with crime and security that often boomerangs into other forms of crime (i.e. dog attacks or human-to-human violence), and the deterioration of infrastructure, evident in power cuts. In this sense the represented private space and its occupant's views are metaphors; analogies of contexts and sensibilities prevalent in the broader socio-political landscape of the country, especially as these pertain to privileged, fearful identities or a particular kind of citizen who has been inhabited by, constituted by, anxiety about crime.

It emerges from the narration that Worm serves as merely another security device intended to guard the narrator and his property. This tactic intersects with the dog being used as narrative device by Barris: the (supposedly) fearsome watchdog serves as a trope figuring a characteristically South African paranoid vigilance against crime. As the story unfolds, we come to understand that the potential psychosis assigned to Worm is a reflection of the narrator's own psychotic inclinations, later realised in Worm's attack and the narrator's response. In this way, the "convention of [dog] ownership" in the story comes to "personify human artifice" (Robles 56). For the narrator, Worm is a possession. He is the dog's owner. The dog is accorded no independent, feeling animal life (an affective potential clearly signalled earlier in the story, where the old woman interacts with Worm). The narrator sees Worm in Descartian terms as a kind of machine which needs to be 'built' through the performativity of training. However, because Worm is not a thing and cannot be controlled by a switch or a remote, "modification" (Armbruster, "Good Dog" 370) requires alternative, authoritative measures 
Canine agents in two South African short stories

to delimit and ideally efface Worm's agency, turning him into the kind of dog the narrator finds most efficient. To this effect, the leash features as a crucial tool. Barris effectively uses the motif of the leash to demonstrate how Worm is subdued, controlled, prevented from "go[ing] at his natural speed" (23), and manipulated to embody aggression. ${ }^{5}$ This is achieved by constantly keeping him bound, reining him in and disciplining his dogness. On the second walk, instead, we encounter the "let[ting] go [of] the leash" (34) at the crucial moment, so that Worm can fulfil his apparently inherent savagery. Of course, for the narrator, his habitual "strangling" (23) of Worm is obligatory because "this is an animal one dares not unchain" (23), although in fact he experiences "a certain nausea, a sour taste in [his] mouth" whenever he "snap[s] the leash" on Worm (22).

That the narrator regards Worm as a kind of horrifying, beastly machine is further evinced in his fantasies and dreams. (The dreams also imply the narrator's ambivalent feelings for the dog; his pent-up rage, as if he himself might at any moment unleash and turn on Worm, eviscerating the animal in giving expression to his own need for the absolute control that he construes as creaturely savagery.) On one occasion, he visualises Worm "stripped of fur and skin, a flayed beast walking" (22). On another, he dreams of him "torn open like a bloody exploded diagram, his organs and limbs detached and spread out" (32). This particular dream, evoked by a storm with gushing winds and thunder that might collapse the neighbour's tree, leaves the narrator baffled and confused as to the "total meaning of these hieroglyphs, to picture the animal from which they sprung" (32). Although a kind of awareness seems to emerge here of the blurred boundaries between species, a flickering recognition of his own animality, the bloody vision, along with other sadistic fantasies, further discloses the narrator's desire to see such acts performed, or to perform such acts, on someone or something else. For instance, when Worm fails to attack either the old lady or her little dog on the first walk, the narrator's annoyance manifests in a vision he is "unable to suppress": "an image of her scalped, exposed" (26). This mental image manifests physically in "[a] gentle, squeezing pressure", "a single clear tendril of pain [...] curling into [his] heart [...] not unpleasant" (26). Not incidentally, the narrator's disparaging deliberations about the woman suggest a loathing of the frail and elderly (the vulnerable), analogous to his latent rage against the underperforming dog. Later, following the night of the storm, when the man and Worm come across a rotten oak tree (not his neighbour's) fallen in the street, he describes it as a "corrupted" corpse, a "bifurcated [pink] trunk", lying "supine" with an "inner arm" (33). The collapsed tree is represented via analogy, imaginatively conflated with sadistic fantasies of violence against a person. The narrator engages in a callous gloating at the oak tree's fate. He views the exposed trunk as repugnant in its "sweaty odour" of "clotted chocolate mould", the body "dense with bacteria" and "rot" (33). For 
a reader, however, the narrator's response to the dead and felled tree reads as an unwitting reflection revealing his own putrid interiority.

Similarly, when Worm finally attacks the spaniel (who incidentally is running free), the narrator's version of what he assumes Worm is experiencing again reflects his sadistic nature. Worm refuses to release, and throttles the dog to inflict "redundant death" (35). Here, Worm has at last internalised the psychosis of his master, and he acts on it, embodying the will to violence the narrator has longed for. An unbridled masculine performativity has claimed Worm; he is transformed from 'dog' to mechanistic agent of his owner's desires to inflict his authority on the vulnerable. The sight of the violence excites the narrator. He notes: "My arms are weak, the edges of my hands tingle [...] I am filled with a grim satisfaction, which I do not really understand. It is a relief, however, a kind of pleasure" (35).

I have referred to Worm as a companion dog rather than a pet. It is evident that the narrator and Worm do not share a mutually nurturing, caring relationship. Nowhere in this story is there any suggestion of acts of kindness or care towards Worm. In fact, it is implied that the dog is abused in various ways. For instance, we are told Worm sometimes trips the "security beams [...] set to ignore any animal weighing less than forty kilograms" (30), which could imply inconsistent feeding habits; he nervously paces up and down at night, "robotic but anxious" (31); and when he is afraid of the thunder, "howling", he is commanded to "shut up!" (32). There is not a single reference to tender touch. Although Worm seems (naturally) excited about going for a walk at the onset of the story, he unravels as the narrative progresses, mirroring his owner's 'nervous condition', which finds expression in the dog attack. Thus the (miserable) life of Worm is mapped.

Seeing that both Worm and the narrator are male (though Worm is never narrated as being aware of biological sex), the use of gender-specific pronouns along with the issue of naming (or lack of naming) are important narrative devices to consider. What might these "imply about identity between otherwise different things" (Martin qtd. in Stibbe 63)? Significant in this regard is how the narrator describes Worm's physical, sensory perceptions and assigns behaviours to him. This is seldom in terms of scent, a dog's most important sense. Instead, the focus is on eyes and sight, itself a projection of the dominance of the visual in human sensory cognition. Worm's eyes, we are told, have "a lugubrious quality [...] liquid with soul", but this the narrator dismisses as "deception", for there is "outrage in [them]" (22). Here, we sense that if Barris draws attention to the sentimentalised attribution of meaning to dogs by humans, the inverse may be even more destructive. In a particularly telling reflection, the narrator notes: "I wonder about his eyesight sometimes. I know that he is blinded by rage, by battle madness. When he gets that look, blood films his eye, its blood vessels thicken and swell to bursting. Surely that must damage his sight?" (24). This delusional militarised reference, and the hypertrophied fixation on a single 'eye' (I), denotes the man's own 
Canine agents in two South African short stories

rage, his maddened mental occupation by the normative violence associated with a culture of authoritarian masculinity. Significantly, too, his own weak eyesight is repeatedly alluded to. He cannot see clearly. By implication, he lacks insight. His view-his "line of sight"- has been narrowed to the jargon of hierarchical soldierly protocols, as in phrasing such as "my line of defence", "patrolling my garden", and "my perimeter is secure" (29). Such discourse suggests, even beyond the generally hierarchical nature of South African life, that he might have served (or, in the 'old South Africa', was conscripted) in the military, police force, correctional services, security or similarly carceral fields, perhaps the source of his militarised thought. The 'worming' emotional correlative in the story between the narrator and the dog highlights contested relations of mastery and abjection in South Africa's troubled socio-political history and the uneasy role of 'the dog': as fearful/wretched instrument of violence and as embodiment of supposed animal savagery inculcated in the service of in/human/e ends. The figure of Worm prompts us to think of the guard or police dog as agent of "redundant death", and also of the fighting dog.

The practice of naming a dog, I argue, like "the choice of dog, reflects desires, anxieties and popular anthropomorphism-involving the projection of the psycho-social self upon the corporeal animals" (Swart 282). The name Worm, together with related associations, metaphorically projects the narrator's sense of diminished self, even though when the narrator introduces us at the onset of the story to "Worm, as I call him" (22), a hierarchy, authorised by "I" is established. In the context of the story, the word 'worm' is rich in ambiguous associations, suggesting softness, vulnerability, insult, deep infestation, and so forth. Further, a worm goes through various life cycle stages, which process foreshadows the dog's behavioural transformation.

The old woman ponders. "What a strange name for a dog like this" (25). Like what? I am prompted to wonder, since Barris does not explicitly distinguish the breed. Similarly, the narrator's racial identity is never mentioned, but much may be inferred about both dog and man. Apart from the narrator's misleading opening statements about Worm's violent temperament, we learn that he is a large, muscular, heavy dog, of "cream and liver" colour (35). These details, coupled with Worm's refusal to "release" when he attacks-which leads the narrator to think, "If I can only detach Worm, make him open his jaws somehow" (35) - signify a functional, structural morphology (lock jaw) that has erroneously been mythologised as specific to breeds such as pit bulls, bull terriers, bull dogs, and boerboels. ${ }^{6}$ Such features have made these breeds popular as defence and attack dogs, their supposedly inherent aggressive behaviours then also coming to symbolise human characteristics such as militant masculinity and aggression. Taken in conjunction with Worm's debased name, I read Barris' omission of reference to the dog's breed as a deliberate narrative ploy that allows him to create a textual space in which

Tydskrif vir Letterkunde 55.3 (2018) 
a reader is tasked ethically to engage with the storyworld via inflections of the accumulated associations that, in a local context, accrue around questions of type, class, category. For example, in limning the characteristics of the dog and the man, the story hints at the extent to which strategic, affective human agency influences qualities often assumed to be biological, species-specific. In other words, we see at work in the relationship between dog and man the metaphorising qualities of the figurative. Additionally, the refusal to classify Worm as a particular breed is a generative ethical lacuna through which Barris is able to comment on the plight of all dogs that are cruelly modified-whether in size, appearance, type or behaviour-for human ends.

Similarly, by not naming the narrator's racial identity, Barris turns his lens to issues associated with class and culture(s) without ruling out a consideration of race. The narrator's standard of living and his neighbourhood designate an implied class affiliation: he has many possessions, the means to purchase expensive security equipment, and the area has a local surveillance group to keep an eye on 'undesirables. Class and racial-cultural affiliation are further implied in his anxiety about threats to his "uninsured" art treasure, hanging in "the lounge" (28), this being his "only heritage-paintings by Boonzaaier, Stern, Jentsch, Maggie Laubser, Ignatius Marx-paintings that capture the country of my youth" (28). The narrative hints, through such cultural status symbols and political nostalgia, that the narrator might be a wealthy white male of a generation in which racist perceptions were common. Here, too, we read these textual markers through the filter of his characteristically aggressive, (self)defensive martial language, which reinforces the idea that he is the product of apartheid and its "militaristic control" (Gqola 113). The 'heritage' signified by the narrator's art collection is worth remarking on. These famous South African painters are renowned for valuable artworks which often represent 'South Africa' in terms of pictorial painterly genres such as pastoral, landscape, and natural scenery. These highly mediated, indeed decoratively stylised, versions of nature, along with the provocatively trained Worm, are the only forms of 'nature' the narrator can tolerate. The narrator works to control his space, to construct it in terms that fit his narrow ideological parameters. In turn, this signals hegemonic thinking that values culturally fixed dichotomies of culture/ nature:human/animal.

In terms of agency, the motif of the dog in this story shows how the dog's agency is brutally undermined through the effects of militant control, thereby evoking affective empathy in the reader, if, as Robles suggests, we pay attention to the "designate[d] silent discourse" or "listen to the mute speech of literary animals" (145). In this way, Barris' textual animal serves as a literary agent that grants agency to animals that endure similar conditions in human-animal life worlds. 
Canine agents in two South African short stories

\section{Shelter(ing) dogs; 'boxed' identities}

I now turn to how the motif of the dog in Murray's story comments on inequities embedded in heteronormativity and the consoling role of the animal in humananimal encounters. In "How to Carry On", Murray merges in evocative ways a range of socio-environmental issues, including the plight of the castoff dog, that remain under-represented in contemporary South African writing, configuring these in relation to a marginalised (stigmatised) transgender child and a transgender youth.

This story too unfolds along a dog walk, the walking being a deliberate move towards liminal spaces, away from the constraints of the claustrophobic suburb. Further, the walking in and through and beyond becomes a synecdoche of the attempts, by the narrating consciousness, to work through a series of unresolved challenges, even crises. I read Murray's employment of the figure of the dog as an important motif for commenting on (linguistic) gender performativity and other ills of society. The textual dogs in this narrative illuminate the limitations of human cultural conceptions of gender identity, and the transgender child instinctively acknowledges the dogs' non-judgemental, non-binary way of being in her own battle with restrictive gender norms. (The dog also signifies related forms of neglect and degradation: the casual discarding of 'superfluous' domesticated animals; the marginalisation of unwanted, supposedly unproductive people, and the effects of consumerism, among them. I cannot explore this complex entanglement in the confines of this paper.)

Before I proceed, a few clarifications. Firstly: despite Murray's unsettling of gender and associated pronouns, I refer to the unnamed main child character as a girl and the unnamed transgender youth encountered in the open field as a boy. Similarly, I am condemned to use the same gendered language in reference to the dogs. The story wants me to do otherwise, and yet sardonically appreciates that I am fated, like the narrator, who is stringently aware of the problematics of such language, to rely on biological sex markers (and pronouns) as essential to understanding the ways of the world, and for finding a route into the storyworld, for analytical purposes. This is in keeping with the uncertain space of the story, which draws particular attention to issues of female masculinity and male femininity, as these relate to the child and the youth, respectively. To highlight the narrative's concern with marginalised identities and materialities, Murray uses powerful metaphors to comment on various forms of "slow violence", to adopt Rob Nixon's terms for violence that is not instantaneous but gradual in the making (2), that permeate South African society, exampled in the locational context of the story. Significant to this representation are the motifs of the shelter dog, the informal settlement, the garbage dump-marginalised animals, people, and sites,

144 layered with discarded consumer trash/histories. I explore how these figurations

Tydskrif vir Letterkunde 55.3 (2018) 
emphasise the ways queer individuals are discursively and physically 'trashed' and 'thrashed' in communities entrenched in "essentialist assumptions of gender and identity" (Francis 539). ${ }^{7}$ My exploration then considers how these devices serve to question and critique the performativity of a dominant, "collective ethos [that] instrumentalizes violence to maintain the appearance of its collectivity" while it "ignores the 'rights of the individual"' (Butler 4), and rejects, according to Halberstam, a "kind of [...] collectivity" amongst such individuals, and those who "live a [supportive] life alongside" (n. p.). I consider Murray's representation of forms of support, or lack thereof, mediated through the conceptual labour of the motif of the dog.

Set in Stellenbosch in the Western Cape, the story is mostly narrated in the third-person, but from the interiority of the transgender child's fiercely compassionate, angered, and frustrated mother (here Murray's redolent metaphorical depictions of human emotions as storms, floods, shattered glass, etc. are piercing). At moments, narration shifts to a second-person perspective, whereby the self (the narrator) and the audience as character are addressed, and behaviours questioned: "She had her reasons. You had yours" (105). There are also shifts in time, interrupting the dog walk with incidents that emphasise the abusive treatment of the transgender character(s) and the plight of the shelter dogs. Along with this fluctuating mode of narration and fragmented structure, we have the inconsistent use of gendered pronouns. I note the universalisation of "the mother" or "the woman", who is and is not the mother, rather than her mother, which also serves to emphasise the issues of gender specificity. Via such nuanced problematics in relation to a narrative that encompasses people and dogs, Murray remarks on the lacunae in mainstream grammar, "where meaning is produced", that fail to address the transgender person-the human cultural constructedness of gender discourse. Such a person is "nestled within the elliptical modes of address that stretch between what can be said, what can be thought, and what feels possible if not probable" (Halberstram n. p.). Caught on this "slippery slope" (Murray 111), "living" in a kind of social-experiential "interregnum" (to adapt Nadine Gordimer's ideas, via Gramsci, of an in-between state), mother, child, and dog(s), each with a set of "morbid symptoms" (Gordimer 2), struggle to find ways 'to carry on'; to cope, in a context that remains so "crapped up" (Murray 107) in judgement and rejection. The title is significant: it is not framed as a question but signals the struggle, for human and dog characters, to survive in the disenfranchising immediacy of the here and now.

The narrative begins by foregrounding the child's longing for a dog, a companion: "the odd girl" who "wants a dog like a farmer wants a wife" (108). Her longing stems from a desire to be accepted, to receive and give the unconditional affection and recognition of being so vehemently denied by peers, adults and the wider community. One father, for example, contemptuously refers to the child

Tydskrif vir Letterkunde 55.3 (2018) 
Canine agents in two South African short stories

as "this [...] thing" (106), a stigma mirrored in the cruel remarks of the children: "[s]he is a boy", "weird", "dof", and "a fat ugly bitch" (105). Here the story not only emphasises reiteration of gender performativity but gestures towards an education system which fails, in a course on so-called life orientation, to teach children about gender and "sexuality diversity" (DePalma and Francis 1687).

In an attempt to temporarily satisfy the child's yearning for "the puppy they will get when Mom is not so busy" (105), and to curb the emotional outbursts which often turn into destructive self-loathing and self-harm, the mother "one Saturday morning" takes the child to the local animal shelter to help "walk the strays" (108). The shelter, situated "on the outskirts of town" (108), a distance from "the neat townhouse neighbourhood" (107) where the family lives, is located "next to the local dump site" (108), which in turn is "next to a [...] cluster of informal housing" (110). With this mapping, Murray at once evokes South Africa's turbulent history of segregation and comments on ongoing conditions of socio-economic inequality and the ways in which discarded things (humans, animals and other used materials) are forced out of view and into squalor on society's margins. These margins are represented as haphazardly squashed into a zone between the affluence of upmarket suburbia and the "nicely ordentlik" pastoral landscape with its "vineyards, coiling and furling" (109) into the distance.

At the shelter, the mother and child meet a few of the many abandoned dogs that need care. There is Rex, "a nice boy", but not allowed out again for the day; Dingo, a "good" dog "but very jumpy"; and a "mottled beige mongrel", an "old bitch", called Buksie $(109,112)$. This last is the dog they are assigned to walk. Buksie is an Afrikaans term often used as a moniker for someone (or a male animal) who is characteristically short, stocky and masculine. I read this detail as Murray's comment not only on the ways in which these animals are categorised as good or bad according to behaviour that is acceptable to the human (even by the shelter's caring, dedicated worker), but also as signifying how Buksie is brought within human parameters: her breed, her age and her body are framed and gendered through naming that designates her in ways of which she cannot, as a dog, be aware. Murray also suggests the unknowability of animal interiority, in describing the cages as lined with newspapers, filled with stories of politics, crime, human sexual desire, and advertisements- "[e]verything gets shat on" (108). The animals have no choice but to perform a basic need where they are forced to sleep and eat. But even beyond this, the story's interest in the complex relations exposed by liminal margins gives a vitally embodied authority to the dogs' visceral animality, setting it at odds with the routinised, institutionalised habits that order the human quotidian and which, by extension, subordinate the dogs' lives.

The human characters in the story constantly interpret embodiment in gendered terms. For example, the woman attendant at the shelter calls the child "my boy" (108) based on her reading of female masculinity, and the mother and child,

Tydskrif vir Letterkunde 55.3 (2018) 
evidently accustomed to such categorising and also themselves uncertain about how best to 'name' the child's preferred gender expression, do not correct her. The discomforting notion of a body_human or animal-being gendered through naming is internalised by the child, and it is the implied suffering of the dog that channels the expression of the child's roiling outrage. On the walk, in stopping her mother from hitting the barking Buksie, the child shouts in confusion, "No! She's just a poor dog, he doesn't understand" (111). Murray works with this switch between gendered pronouns throughout, and this is clearly more than a reflection merely of linguistic interference in a community where Afrikaans and English awkwardly intersect. Consider, for instance, the pronominal volatility when the mother and child encounter the trans youth, and when the child on return to the shelter calls a terrier "boy", and then corrects herself "Oh, hullo girl" (113). The story clearly wishes to draw readers into a narrative terrain where erring, error, the errant, and mis/take are necessary provocations to settled normativity. (I return to this later.)

Mother. Child. Dog: the little female party sets out past the dump towards a scrappy open field beyond. The dump is described as "an old photograph of open-cast prospecting, a gold mine" (109), layering the present with history, and acknowledging that apparently obvious reality is always mediated by inflections of aesthetics, a consciousness of artful representation. The image resembles history (the trope of the mine) - a corpse laid out, and it reflects, as a microcosm, continued inequities where people and things, literally and figuratively, are dumped and some are forced to forage through the trash in an attempt to eke out a living (to make sense of life). Beyond the dump, near the settlement, they come across "a thin black girl in shorts" carrying "a camo-print backpack"-a "makeshift girl" (110). At the sight of this figure, Buksie proceeds to bark incessantly. The narrator regards Buksie as "an embarrassment", a description which gestures to a guilt-ridden political correctness-'dogs should not bark at black people', and threatens to hit the dog. The child interprets the dog's behaviour differently; for her the dog is doing what it is doing in its dogness-it barks at strangers. The 'makeshift girl', on the other hand, turns and makes eye contact with the dog, addresses it directly as in 'I see you' and speak to you, an act of recognition: "Jjjjjjy! Jy's too fokkin tjeeky" [you are too fucking cheeky] (110-1). She then settles nearby and proceeds to undress, to change her outfit, to make visible the human body. The narrator turns her gaze on this body, noting: "He is all wiry muscle. Small breasts a padded pushup bra. He changes his hair for a longer, blonder length, and this time settles the wig carefully, tucking under, adjusting" (111). To emphasise human response to the revealed male body that now performs femininity, Murray brings the dog back into focus, who at this moment is anthropomorphised, "Even Buksie is speechless" (111, my emphasis), signalling human speechlessness before the person who 'nestles within the elliptical modes of address' (Halberstam n. p.). Murray again 
Canine agents in two South African short stories

signals the unknowability of animal interiority, in how they might sense, see or interpret human biology, or their own biology, so easily gendered by humans because of the visibility of the animal's biological sex. Here, I read the dog's "gaze" as "a reminder of what it might mean for humans to have a different relation to their bodies" (Green 118). To this effect, the child's response is telling: she senses a shared innocence about the affairs of human identity construction. Well aware of the power of the human gaze at this stage (age), as events in the story show, the child says to the mother: "Stop staring!", "[...] It's not your life. You can't make the choice" (Murray 111). The italicised 'you' incriminates both the narrator/ mother and audience. Murray, as an academic, intimates scholarly debates about preference, orientation and expression in gender and sexuality studies. The child aligns herself with the companion dog, who in her silence offers no judgement: the girl "spits a single word-'People!'-then turns away to walk the loan dog" (112). The marginalisation of (transgender) identities is emphasised in another moment when the child says, "You don't know, mommy. What it's like. You don't understand", to which the narrator responds, in musing, "Which is true. The cold hard truth of it" (107).

Towards the end of the story, we learn about the murder of a teenage boy (who is not necessarily "that boy even the girl" (112) the mother and child encountered on the walk). His body has been found discarded near the dump. Here, Murray draws attention to the high levels of gender violence in the country, the prevalence of homo/transphobia, "including cases of rape and murder" (Lease and Gevisser 158), the ignorance of news reporters who still refer to trans persons or drag artists as "cross-dresser[s]" (112), and how essentialist, moralising gender and identity codes prevail amongst all members of society, regardless of class or race, and despite clichéd rhetoric about tolerance which does not convey recognition. All races and classes are implicated in this part of the narration, where characters respond to the boy's murder (112). The murdered teen is decried as someone marginal, outside the parameters of societal norms: "the dump was his livelihood", "he had no parents to look out for him" (112). The story suggests in a very selfreflexive way an awareness of privilege: the mother and child come from a more affluent context than the youth. The child has, despite all the mother's anger and frustrations, someone who stands by her side in the struggle to 'carry on', whereas the youth seemingly had nobody; the child has the opportunity to find comfort in the presence of a nonhuman companion who associates without judgement, who licks the child's face in affirmation when, and despite, being returned to a cage at the shelter.

In the concluding section of the story, where the end of the dog walk is recalled, Murray skilfully emphasises, in metaphorical terms, the conundrum for both human and animal characters of how to carry on. On return to the shelter, the 148 child tells the dog, "Bye bye, Buk-sie. Back in your box-sie" (112), as must she.

Tydskrif vir Letterkunde 55.3 (2018) 
The blunt reality for the child on how to negotiate her 'boxsie', is evinced in her behaviour when she corrects herself, "overwrites a self that doesn't fit the pretty imperfect mould", for calling the "little terrier" in another cage 'boy' and not 'girl': "Oopsie! [...] I nearly made a wrong one that time, didn't I. But that's okay, it's only me" (113). Buksie's immediate reality is that her freedom, as a 'loan' dog, was temporary, and in all probability her association with this human pair is terminated, for the child decides, "Next time. We must get that foxy one" (113). The use of 'foxy' to describe the female terrier, further implies the child's resignation to the protocols of gender, sexual discourses, while the future of the old Buksie seems grim. This makes doubly significant the narrator's reflection. When, asks the narrator, saddened and disillusioned, will the time come, when "the poor would inherit the earth [...] the meek and downtrodden would enjoy the love and life they deserve" (113). The phrasing implies a utopian vision that remains far from realisation for human and animal, whether in South Africa's dysfunctional democracy, or beyond, or in the disenfranchised world of the discarded animal.

Thus, beginning with 'the dog' as the familiar object of childhood desire, and working through human/dog relations to produce 'the dog' as an ambiguous figuration of being-in-formation, and also of destructive social desire, Murray effectively and affectively uses the trope or motif of the dog to draw attention to matters of agency and marginality.

\section{Conclusion}

In metaphorising the figure of the dog, limning characteristics of the human and the animal, Barris and Murray comment on human-animal relationships and encounters, and how the use of the dogs as imaginative devices draws attention to issues of essentialist gender norms and other inequities in contemporary South African society. The dog, as an important motif, illuminates the limitations of human cultural conceptions of gender performativity in each narrative's treatment of either violent, militant masculinity or the marginalisation of transgender identities, respectively. Distillation occurs via the motif of the dog and the trope of the dog walk, as a purposive local conceptual configuration of the more habituated abstract narrative motif of the 'journey', to establish a multifaceted imaginative conversation between the texts, and between mediated animal-human life worlds. This dialogue highlights the failure of South African society to recognise the vulnerability and suffering of human and animal subjects, entangled fragilities, and the dog, as literary agent, guides us to consider how forms of power and abuse undermine agency of the marginalised human-animal. 
Canine agents in two South African short stories

\section{NOTES}

1. "The Life of Worm" was first published in New Writing from Africa (2009). It was re-published in A Life in Full and Other Short Stories (2010), shortlisted for the Caine Prize for African Writing; and included in Barris' collection, The Life of Worm \& Other Misconceptions (2017). In this article I work with the latter version.

2. I acknowledge discourses from various disciplines that regard humans as animals based on a "shared common origin" (Robles 3), but I use 'human' and 'non-human' or 'human' and 'animal' in this article in view of interpretative practices in the fields of ecocriticism and animal studies in the humanities. My use intends to distinguish between human and animal characters (often unnamed) in the chosen narratives while recognising distinctions in each grouping, as Robles proposes, in the sense that not all humans are the same, just as not all "members of the animal kingdom" are the same (3).

3. According to Richards et al., "non-binary or genderqueer genders" are terms used for people who have "a gender which is neither male nor female and may identify as both male and female at one time, as different genders at different times, as no gender at all, or dispute the very idea of only two genders" (95).

4. I used Google Maps to contextualise the setting.

5. In "Walking with Thoreau in Mind and Dogs on Leash", Karla Armbruster insightfully argues for walking a dog (on and off a leash) while paying "attention" to the dog's "sensory capabilities" (68).

6. The boerboel is a South African breed of which " $t$ the origin and trajectory [...] remains still largely unknown" (Van Sittert and Swart 33).

7. I am cognisant of debates about the use of the term queer in (South) African Gender and Sexuality Studies, and I use the term, as described by April Sizemore-Barber, as "an umbrella term for non-heterosexual identities" (117).

\section{WORKS CITED}

Armbruster, Karla. "Walking with Thoreau in Mind and Dogs on Leash." Forum for World Literature Studies vol. 6, no. 1, 2014, pp. 68-78.

“'Good Dog': The Stories We Tell about Our Canine Companions and What They Mean for Humans and Other Animals." PLL: Papers on Language \& Literature. vol. 38, no. 4, 2002, pp. 351-76.

Attridge, Derek. “Age of Bronze, State of Grace: Music and Dogs in Coetzee’s Disgrace." Novel: A Forum on Fiction vol. 34, no. 1, 2000, pp. 98-121.

Baderoon, Gabeba. "Animal Likenesses: Dogs and the Boundary of the Human in South Africa." Journal of African Cultural Studies vol. 29, no. 3, 2017, pp. 345-61.

Barris, Ken. "The Life of Worm”. The Life of Worm \& Other Misconceptions. Kwela, 2017.

Butler, Judith. Bodies that Matter: on the Discursive Limits of "Sex". Routledge, 1993.

Chapman, Michael. Southern African Literatures. Longman, 1999.

Cock, Jacklyn. Colonels and Cadres: War and Gender in South Africa. Oxford U P, 1991.

DePalma, Renée \& Dennis Francis. "South African Life Orientation Teachers: (Not) Teaching About Sexuality Diversity." Journal of Homosexuality vol. 61, no. 12, 2014, pp. 1687-711.

Francis, Dennis. "You Must Be Thinking What a Lesbian Man Teacher Is Doing in a Nice Place Like Dipane Letsie School?': Enacting, Negotiating and Reproducing Dominant Understandings of Gender in a Rural School in the Free State, South Africa." Gender and Education vol. 26, no. 5, 2014, pp. 539-52.

Gordimer, Nadine. “Living in the Interregnum.” The New York Review of Books, 20 Jan. 1983.

Tydskrif vir Letterkunde 55.3 (2018) 
Gqola, Pumla Dineo. “How the 'Cult of Femininity' and Violent Masculinities Support Endemic Gender Based Violence in Contemporary South Africa.” African Identities vol. 5, no. 1, 2007, pp. $111-24$.

Green, Louise. "The Language of Dogs: Intermediate Forms in Global Culture." Current Writing: Text and Reception in Southern Africa vol. 18, no. 1, 2006, pp. 103-18.

Halberstam, Jack. "Listen: Jack Halberstam on 'Trans* Bodies and Power in the Age of Transgenderism". Swarthmore College News \& Events. 22 Dec. 2016. <www.swarthmore.edu/ news-events/listen-jack-halberstam-trans-bodies-and-power-age-transgenderism>. Accessed 5 Dec. 2017.

Haraway, Donna. The Companion Species Manifesto. Prickly Paradigm, 2003.

Heyns, Michiel. "'Separate Families, Separate Worlds, the Same Native Space': Aspects of the South African Short Story." Current Writing: Text and Reception in Southern Africa vol. 17, no. 1, 2005, pp. $167-84$.

Hines, Sally. "What's the Difference? Bringing Particularity to Queer Studies of Transgender." Journal of Gender Studies vol. 15, no. 1, 2006, pp. 49-66.

Kostelac, Sofia. "'Imposter, Lover and Guardian': Damon Galgut and Authorship in 'Post-Transition' South Africa." English Studies in Africa vol. 53, no. 1, 2010, pp. 53-61.

Lakoff, George \& Mark Johnson. Metaphors We Live By. U of Chicago P, 1980.

Lease, Bryce \& Mark Gevisser. "LGBTQI Rights in South Africa." Safundi vol. 18, no. 2, 2017, pp. 156-60.

Libin, Mark. "Dog-Angels in Wolf Time: Locating the Place of the Human in Marlene van Niekerk's Triomf." Journal of Postcolonial Writing vol. 45. no. 1, 2009, pp. 37-48.

MacKenzie, Craig. Transitions: Half a Century of South African Short Stories. Francolin, 1999.

McHugh, Susan. "Literary Animal Agents." PMLA vol. 124, no. 2, 2009, pp. 487-95.

Murray, Sally-Ann. "How to Carry On”. Incredible Journey: Stories that Move You. Ed. Joanne Hichens. Burnet Media, 2015, pp. 104-13.

Neumann, Birgit \& Ansgar Nünning. "Metanarration and Metafiction." The Living Handbook of Narratology. Eds. Peter Hühn et al. Hamburg U P, 3 Dec. 2012. <wikis.sub.uni-hamburg.de/lhn/ index.php/Metanarration_and_Metafiction>. Accessed 17 Nov. 2017.

News24. "Zuma comments cause canine chaos." News24 Archives, 27 Dec. 2012. <https://www. news24.com/SouthAfrica/News/Zuma-comments-cause-canine-chaos-20121227>. Accessed 7 Sep. 2018.

Nixon, Rob. Slow Violence and the Environmentalism of the Poor. Harvard U P, 2011.

Richards, Christina et al. "Non-Binary or Genderqueer Genders." International Review of Psychiatry vol. 28 , no. 1, 2016, pp. 95-102.

Robles, Mario Ortiz. Literature and Animal Studies. Routledge, 2016.

Sizemore-Barber, April. "Archival Movements: South Africa's Gay and Lesbian Memory in Action." Safundi vol. 18, no. 2, 2017, pp. 117-30.

Stibbe, Arran. Ecolinguistics: Language, Ecology and the Stories We Live By. Routledge, 2015.

Swart, Sandra. "Dogs and Dogma: A Discussion of the Socio-Political Construction of Southern African Dog 'Breeds' as a Window onto Social History." Canis Africanis: A Dog History of South Africa. Eds. Sandra Swart \& Lance van Sittert. Brill, 2008, pp. 266-87.

Tambling, Jeremy. Allegory. Routledge, 2010.

Van Sittert, Lance \& Sandra Swart, eds. Canis Africanis: A Dog History of South Africa. Brill, 2008.

Woodward, Wendy. "Social Subjects: Representations of Dogs in South African Fiction in English." Canis Africanis: A Dog History of South Africa. Eds. Sandra Swart \& Lance van Sittert. Brill, 2008, pp. 235-62. 